\title{
Evaluating Plant Extracts Effects against Aethinatumuda Pests of Honeybees (Apismellifera)
}

\author{
DeressaKebebe*, Alemayehu Gela, TeferiDamto, MeseretGemeda, GemechisLeggese \\ Oromia Agricultural Research Institute, Holeta Bee Research Center, Oromia, Ethiopia
}

*Corresponding Author: DeressaKebebe, Oromia Agricultural Research Institute, Holeta Bee Research Center, Oromia, Ethiopia

\begin{abstract}
The honeybee is the most useful insect to man but their productive potential is reliant on their health conditions. The pests not only cause economic loss but also because ecological problems related to the role of honey bees, as the most vital pollinators of the World. The aim of this study was to evaluate and identify the efficiency of some plant-based biocides to develop alternative method of controlling honeybee pests to the safest of bee products. For this purpose, Euclaptusglobulus, Calpurnia aurea, Ocimumbasilicum, Allium sativum,Cymbopogoncitratus,Menthapiperita and Ocimumgratissimumplant species were collected, dried under shade and grinded and the oil was extracted. The botanical extracts were prepared in different concentrations levels and applied on small hive beetles and honey bees. Plant extracts exhibited variable responses to small hive beetles (Aethinatumuda) and honeybees. Ocimumgratissimum and Ocimumbasilicum leaf extracts caused $100 \pm 0.00$ percent mortality after application of $70 \%$ dose of plant extracts while Euclaptusglobulus and Cymbopogoncitratusleaf extract was the nextkillers of small hive beetles after application for 48 hours. Calpurnia aurealeaf extract is proved to be safer to honeybees (A. mellifera. Even though this result shown that the effective plant extracts can beused to develop botanicals to control pest population, proving the efficacy of the extracts in beehives on the pests is important in the future study.
\end{abstract}

Keywords: Honeybee, Plant extract, Small hive beetles, Effectiveness

\section{INTRODUCTION}

The honeybee is considered of great economic importance not only for the production of honey, wax, and other valuable products, but also for crop pollination and environmental stability. The essential and valuable activities of bees depend upon beekeepers maintaining a healthy population of honeybees, because like other living organisms, bees are subjected to many diseases and pests (Ritter and Akratanakul 2006).Many developing countries are trying to improve the quality of their honey products but they frequently encounter widespread obstacle in apiculture. Among many interrelated factors, infestation of honeybee colonies by pathogens and pests is the prominent ones that inflict enormous loss to the potential beekeeping production. In tropical countries pests and predators of honeybees are more prevalent and affect honeybees than diseases and cause loss of colonies and their products(Morse and Now ogrodzki 1990).Using synthetic pesticide against bee pests and diseases is not essential in order to absence the risks of contaminating honey and beeswax with residue. Furthermore, beekeepers in developing countries may not be able to afford synthetic pesticides.

The development and promotion of alternative means of technologies against bee pests is so extremely important. This would have advantages of enhancing environmental quality and economic viability of individual beekeeping operations, protect human health and safety by preventing the risk of contaminating honey and hive products, and promote the well-being of honey bees. Botanical pesticides are safer to users and environment because they are biodegradable and break down into harmless compounds within few hours in the presence of sunlight (Buss A. and Park-Brown S., 2002). Furthermore, botanical pesticides are encouraged over conventional pesticides because, they affect only target pest, effective in every small quantity, decompose quickly and provide the residue free food and a safe environment to life (Pedigo, 1998). When incorporated with integrated pest management programs, botanical pesticides can greatly decrease the use of conventional pesticides (Parmar and Devakumar 1993; Khater 2012).For these reasons, the more recent approach to control 
honey bee pests and diseases has been inclined to use relatively safe natural products of plants and plant derivatives.

Plant based pesticides have been adopted in different countries and cultures with their own specific indigenous knowledge and parallel standards and methods for evaluation. For instance, the plants of families Myrtaceae, Lamiaceae, Asteraceae, Apiaceae and Rutaceae are highly targeted for anti-insect activities against specific insect orders like Lepidoptera, Coleoptera, Diptera, Isoptera and Hemiptera (Khater, 2012).

Crude extracts and essential oils have been explored for repellent, fumigant, larvicidal and adulticidal activities against the various insect's orders. Evidence showed that some botanical pesticides are effective against bee pests and disease (StanghelliniandRaybold, 2004; Zaitoun, 2007). For example, essential oils from thymol, eucalyptus and wintergreen have been commonly used for treating honey bee afflictions, including infestations of parasitic mites (varroa and Acarine (tracheal) mites(Khater, H. F. 2012;Calderone, 1999).However, the safety, effectiveness and quality of botanical products depend on the quality of their source materials and how elements are handled through production processes.

Ethiopia has a vast flora and fauna that have potential for developing natural products into commercial technologies. Traditional use of plants and plant derivatives for pest control and medicinal value is long time established in the country. A diversity of plant species is traditionally used as repellents and insecticidal effect in Ethiopia (Abebe et al., 2003; Berhanuet al., 2006). However, scientific evidence from tests to evaluate the safety and effectiveness of traditionally used plant products against major pests and pathogens is very limited. Particularly, technologies to explore the existing traditionally used plant species to the more advanced practice against honeybee pests is absent in the country. Hence, the aim of this study was to evaluate the effectiveness of the most common traditionally used insect repellent and inducing plant species oil extracts against small hive beetles that help improve access to the local beekeepers to safer, effective, reproducible and affordable management of honeybee pests.

\section{Material AND MethodS}

\subsection{Study Area}

The experiments were conducted at laboratory of Holeta Bee Research Centre Oromia Agricultural Research Institute, Oromia regional state in Ethiopia during July 2016-July 2018. Honeybee A.mellifera colonies were transferred in Langstroth beehives and naturally infested with small hive beetles in the duration of two years.

\subsection{Plant Parts Collection and Identification}

Seven plant speciesessential parts were collected based on indigenous knowledge, previous research work and literature like E.globulus (leaves), C.aurea (leaves), O.basilicum (leaves), A.sativum (bulbs), C.citratus (leaves) and O.gratissimum (leaves).Different parts of these plant species such as leaves and bulbs of plants were collected from Ejere, Menegesha, Alagae and Holeta areas of Oromia region in Ethiopia.

\subsection{Sample Preparation}

The collected plants parts were kept at room temperature. Then, the leaves and bulbs were dried under shade and grinded with ultra-centrifugal millin Holeta Agricultural research Centre animal nutrition laboratory and the grinded sample was stored in a plastic bottle.

\subsection{Plant Oil Extraction}

Three gram (3g) of dry sample was weighed to within milligrams in an extraction thimble; it was placed and shaked to dissolve it in the extraction unit. The parts were dissolved in organic solvent (hexane).The flask was connected to hexane containing at $2 / 3$ of total volume to the extractor until 4 hours. When finished, the hexane was evaporated by in rota evaporator. Hexane was removed by rotor evaporation under vacuum and the oil was picked in a vial. The extract was put in vial and stored at $0 \circ C$ until time for use. The flasks were cooled in a dryer and weighed them. Then, the extracts were dissolved in distilled water to obtain different concentrations (70\% and 100\%) for bioassay tests on small hive beetles while $100 \%$ was used to detect the safety of the extracts on honey bees. 
Distilled water and hexane were used as positive and negative controls, respectively. The controls were without plant extracts however distilled water was used for concentration levels preparation purpose.

\subsection{Screening of Plant Extracts Oils}

Even though 10 plant extracts oils were tested, only the six extracts against small hive beetles with a positive effect were mentioned in this paper which was effective on the beetles in laboratory.

\subsection{Adult Small Hive Beetles Collection}

Adult small hive beetles (Aethinatumuda) were collected from bee colonies using small hive beetle trap (modified Langstroth type hives), according to (Alemayehu et.al, 2018). The hives were modified with open underneath on the bottom board and covered with mesh wires. From the back of the hives, a slot of corrugated cardboard $(45 \mathrm{~cm} \times 45 \mathrm{~cm})$, with one surface peeled to expose the ridges were inserted in to the bottom board of each bee hive with the ridged side down. Underneath of the frames on the bottom board were covered with mesh wires which allow SHB to enter and hide in the corrugations, but exclude honey bees to fit the bottom board. The inserts were removed with small hive population and then, adult beetles were trapped in the corrugated and transferred into sampling bottles.

\subsection{Testing of Plant Extracts Safety on Honeybees}

Laboratory bioassay was tested on safety of the plant extracts on honeybees. Fumigant toxicity bioassay on honeybees safety were tested using the plant extracts. The toxicity effect of was tried by direct feeding, contact or fumigation. Three hours prior to each feeding trial, 10 adult bees for each treatment were sampled from healthy colonies and brought to the laboratory in cages. Safety of the plants extracts were tested on honeybees (A. mellifera) as shown in Figure 3.

\subsection{Bioassay Test on Aethinatumuda}

Laboratory bioassay was tested against adult small hive beetles. The experiment was tried on five small hive beetles (Aethinatumuda). Fumigation technique was used in all approach. Collection of data was carried out at different time interval after application of different

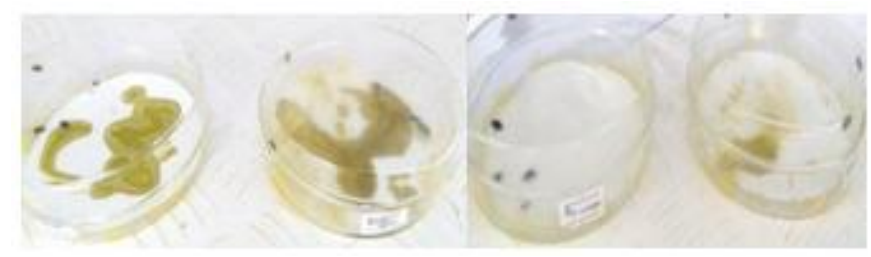

Figure1. Bioassay Test on Aethinatumuda

Concentrations of plant extracts during bioassay testing of small hive beetles. The population of pests were noted and recorded after each plant extract applications.

Biopesticidal effects activity of 6 plant extracts was performed using fumigation test according to Drummond et al. (1976). Serial dilutions of plants extracts oils (70\% and 100\%) were prepared in distilled water. Anti-pest effects of each dilution were tested by immersing a group of 5 small hive beetles in a Petri dish containing different percents of the extracts. The experiment was performed in Petri dishes for the times in three replications for each concentration levels. The mortality was recorded by counting dead small hive beetles (alive and dead) and the corrected mortality rate reported as the percent mortality rate of the pests calculated as Abotts (1925)as mentioned by equation below:

$$
\text { Corrected Mortality= } \frac{\text { \%Treated mortality }-\% \text { control mortality }}{100-\% \text { control mortality }} \times 100
$$

\subsection{Statistical Analysis}

The experiments were conducted in petri dishes to test the efficacy of the plant extracts against small hive beetles and safety of the extracts on honeybees. The effect was calculated according to Abbott (1925). The obtained results were submitted to means and the mean values were compared by 
Turkey's test $(\mathrm{P}=0.05)$ calculated by the program SPSS 20). Mortality rate was calculated as; mortality is equals to after treatment the number of died mites divided by before treatment the number of mites times 100 percent.

\section{RESUltS AND DisCUSSION}

A total of seven extracts from different medicinal plants were tested for efficacy against Varroa Destructors and six plant extracts were used for Aethinatumuda. The efficacy of plants extracts of E.globulus (leaves), C.aurea (leaves), O.basilicum (leaves), A. sativum (bulbs), C.citratus (leaves) and O.gratissimum (leaves) at a concentration of $70 \%$ and $100 \%$ doses of the extracts were tested against small hive beetles (Table1).

The result showed that C.citratus essential oil extract has pronounced effective followed by O.gratissimum and O.basilicum on Aethinatumuda. Eighty percent (80\%) mortalities were recorded for C.citratus extract, against Small hive beetles within 48 hours of exposure at a concentration of 70 and $100 \%$, respectively. Mortality of small hive beetles ((Aethinatumuda) increased as concentration and exposure time to the plant extracts increased.

\subsection{Aethinatumuda}

Six plants species extracts used after screening to test the efficacy on Aethinatumudas had been shown different response to the extracts. Different concentration levels of the plant extracts applied on the small hive beetles were $70 \%$ and $100 \%$. The botanical extracts were diluted using distilled water. Both Ocimum plant species oil extracts are endorsed for future bio-pesticide development against the small hive beetles control. The effect of the extracts was observed in time intervals on pests to observe the mortality rates and the result is shown in the following Table 1.

Table1. Aethinatumuda mortality rate at different concentration level of plant extracts

\begin{tabular}{|c|c|c|c|}
\hline Treatment & $\mathrm{N}$ & \multicolumn{2}{|c|}{ Mean \pm SE mortality rate at concentration level } \\
\cline { 3 - 4 } & & $\mathbf{7 0 \%}$ & $\mathbf{1 0 0 \%}$ \\
\hline Allium sativum & 5 & $40.0 \pm 11.5^{\mathrm{bc}}$ & $40.0 \pm 0.0^{\mathrm{c}}$ \\
\hline Eucalyptus globulus & 5 & $60.0 \pm 0.0^{\mathrm{b}}$ & $66.6 \pm 0.0^{\mathrm{bc}}$ \\
\hline Cymbopogoncitratus & 5 & $66.7 \pm 17.6^{\mathrm{ab}}$ & $100.0 \pm 17.6^{\mathrm{ab}}$ \\
\hline Ocimumgratissimum & 5 & $100.0 \pm 0.0^{\mathrm{a}}$ & $100.0 \pm 0.0^{\mathrm{a}}$ \\
\hline Ocimumbasilicum & 5 & $100.0 \pm 0.0^{\mathrm{a}}$ & $40.0 \pm 0.0^{\mathrm{c}}$ \\
\hline Calpurnia aurea & 5 & $20.0 \pm 0.0^{\mathrm{cd}}$ & $100.0 \pm 0.0^{\mathrm{a}}$ \\
\hline Hexane (standard control) & 5 & $100.0 \pm 0.0^{\mathrm{a}}$ & $00.00 \pm 0.0^{\mathrm{d}}$ \\
\hline Water (negative control) & 5 & $00.00 \pm 0.0^{\mathrm{d}}$ & \\
\hline
\end{tabular}

Means with the same alphabets down the column are not significantly different from each other using Tukey at 0.05 .

The result indicates that both O.basilicum and O.gratissimum had caused highly significant $(100 \pm$ 0.0 ) effect on small hive beetle as that of standard chemical (hexane). This two plant species extracts are showed effective to cause Aethinatumuda mortality even both at $70 \%$ and $100 \%$ concentration levels. This finding is in line with the fact that Ocimum plant extracts are known for their medicinal purpose for different diseases and pest controls as indicated in some literatures (Pitan et. al., 2015). However, C.aurea oil extract is not significantly $(40.0 \pm 0.0)$ caused SHB mortality as compared to negative control (water), indicating the least effective on the beetles. In other way, C.citratus and E.globulus was showed relatively significant effect on SHB as compared to the negative control.

Leaves extracts of O.gratissimum and O.basilicum caused $100 \pm 0.00$ percent mortality after application of $70 \%$ dose of plant extracts while E.globulus and C.citratusleaf extract killed $66.67 \pm 17.64$ to $80 \pm 0.00$ percent of small hive beetle's population after application for 48 hours as mentioned (Table 1). Pitan and Co-workers mentioned that n-hexane extracts plants O.gratissimum caused 100 percent mortality of insects within six hours which shown rapid action of the plant extracts and situations it to play with synthetic pesticides that are highly favoured because of their quick action among others.A.sativum and C.aurealeaves extracts proved less effective to small hive beetles. Pitan and coworkers stated that O.gratissimum has ability to repel and induce mortality in $A$. tumida. The insecticidal activities of plant extracts have been reported by many authors. The highest mortality of small hive beetles at one hundred percent during application of O.gratissimum which is similar to findings of Pitan and Co-workers (Pitan et. al., 2015). 


\subsection{Honeybees safety}

Adult honeybees were kept at room temperature, without food to make them hungry. Each plant extracts were dissolved with distilled water to be tested. Each liquid sandwich was comprised $100 \%$ for each concentration of each extracts, 2 cages, each with 10 honeybees, were fed the liquid sandwiches. The bees were fed on control each time. During this time the numbers of dead bees were monitored within time intervals.

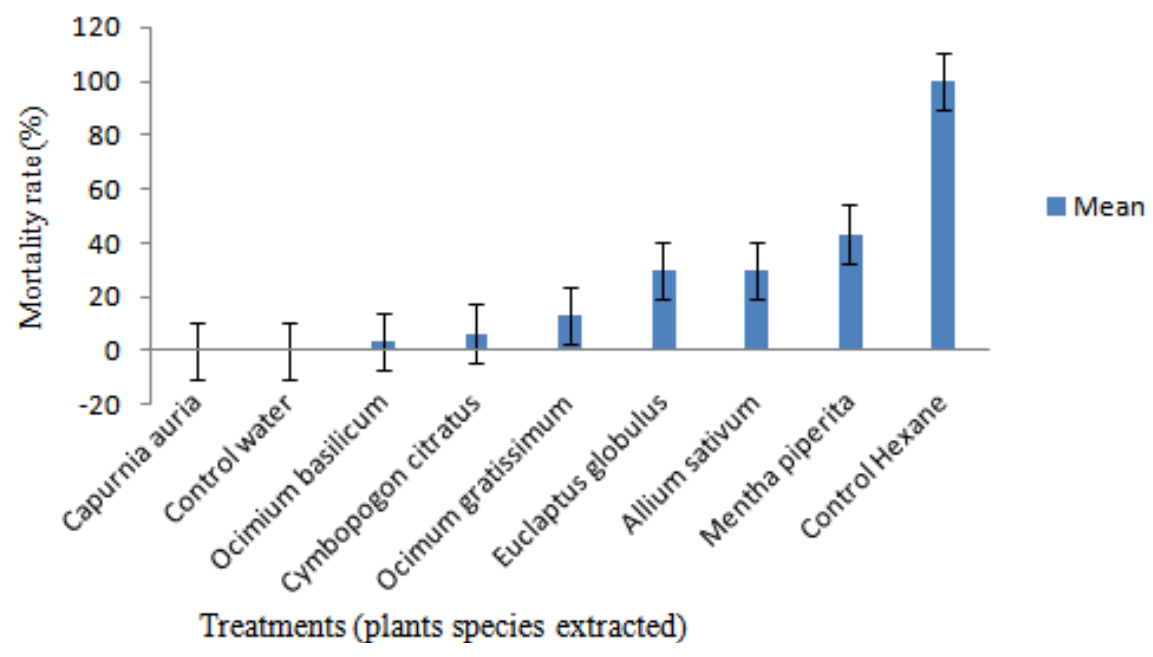

Figure2. Effect of plant extracts on honeybees

C. aurea extract was the safest of all plant extracts while O.basilicum and C. citrates shown less mortality after application in 24 hours intervals. Present results also showed that the plant extracts such as M.piperita, A.sativumand E.globulus were unsafe to honey bees at 100 percent doses after 24 hours' time interval, respectively. The plants extracts oil safety in decreasing order is C.auria, O.basilicum, C.citratus, O.gratissimum, E.globulus, and A. sativum. This result indicated that the safest and most effective plants species may be used to develop biopesticides to control the pests of honeybees.

\section{CONCLuSion}

Plant extracts exhibited variable responses to Aethinatumuda population. The finding of this study implies that Ocimum plants species leaf extracts caused highest percent mortality of Aethinatumuda after application of 70 percent concentration of the plant extracts in 48 hours. C.auria showed the safest of all extracted oils on honeybees. Therefore, the plant species can be developed as botanical pesticides to control target honeybee pests. The efficacy should be also checked on pests-infested larvae of honeybees. Identification of active components from the effective plants oils for the control of honeybees pests and safety to the pollinators should also be studied in the future.

\section{REFERENCES}

[1] Khater, H. F. (2012). "Prospects of botanical biopesticides in insect pest management." Pharmacologia 3(12): 641-656.

[2] Parmar, B. and C. Devakumar (1993). Botanical and biopesticides, Westvill Publishing House.

[3] Ritter, W. and P. Akratanakul (2006). "Honey bee diseases and pests: A practical guide, agricultural and food engineering technical reports." Rome, Italy: FAO, Food and Agriculture Organization of the United Nations.

[4] Morse, R. A. and R. Nowogrodzki (1990). Honey bee pests, predators, and diseases, Comstock Publishing Associates

[5] Buss, E. A. and S. G. Park-Brown (2002). "Natural products for insect pest management." UF/IFAS Publication ENY-350. URL: http://edis. ifas. ufl. edu/IN197.

[6] Pedigo, L. P. (1998). Entomology and pest management, Prentice-Hall International.

[7] Khater, H. F. (2012). "Prospects of botanical biopesticides in insect pest management." Pharmacologia 3(12): 641-656.

[8] Stanghellini, M. S. and P. Raybold (2004). "Evaluation of selected biopesticides for the late fall control of varroa mites in a northern temperate climate." American Bee Journal 144(6): 475-480. 
[9] Zaitoun, S. T. (2007). "The effect of different Mediterranean plant extracts on the development of the great wax moth Galleria mellonella L.(Lepidoptera: Pyralidae) and their toxicity to worker honeybees Apis mellifera L.(Hymenoptera: Apidae) under laboratory conditions." Journal of Food Agriculture and Environment 5(2): 289.

[10] Zaitoun, S. T. (2007). "The effect of different Mediterranean plant extracts on the development of the great wax moth Galleria mellonella L.(Lepidoptera: Pyralidae) and their toxicity to worker honeybees Apis mellifera L.(Hymenoptera: Apidae) under laboratory conditions." Journal of Food Agriculture and Environment 5(2): 289.

[11] Rosado-Aguilar J. A., Aguilar-Caballero,A, RodriguezVivas, R. I. Borges-Argaez, R.

[12] Garcia- Vazquez, Z.and MendezGonzalez, M. "Acaricidal activity of extracts from alliacea (Phytolaccaceae) against the cattle tick, Rhipicephalus (Boophilus) microplus (Acari ixodidae)," Veterinary Parasitology,vol.168,no.3-4,pp.299-303,2010.Petiveria

[13] Pamo, E. T. Tendonkeng, F.J., Kana R. et al., "A study of the acaricidal properties of an essential oil extracted from the leaves of Ageratum houstonianum," Veterinary Parasitology, vol. 128, no.3-4,pp.319323,2005 .

[14] Solomon A., Workalemahu A., Jabbar M. A., Ahmed M. M., and Hurissa B., "Livestock marketing in Ethiopia: a review of structure, performance and development initiatives,"Socio-Economic and Policy Research Working Paper 52, IILR Institute, Nairobi, Kenya, 2003.

[15] Pitan et. al., Laboratory Evaluation of Insecticidal Activities of Some Botanicals against Four Insect Pests of Honey Bees (Apis mellifera L.) International Journal of Applied

[16] Agricultural and Apicultural Research Faculty of Agricultural Sciences, pp 179-180, LAUTECH, Ogbomoso, Nigeria, 2015.

Citation: DeressaKebebe, et.al. " Evaluating Plant Extracts Effects against Aethinatumuda Pests of Honeybees (Apismellifera)". International Journal of Research Studies in Biosciences (IJRSB). 7(11), pp. 14-19. DOI: http://dx.doi.org/10.20431/2349-4050.0711003

Copyright: () 2019 Authors this is an open-access article distributed under the terms of the Creative Commons Attribution License, which permits unrestricted use, distribution, and reproduction in any medium, provided the original author and source are credited. 